\title{
Intravenous and Peritonsillar Infiltration of Ketamine for Postoperative Pain after Adenotonsillectomy: A Randomized Placebo-Controlled Clinical Trial
}

\author{
Saeed Khademi ${ }^{\mathrm{a}}$ Fariborz Ghaffarpasand ${ }^{\mathrm{c}}$ Hamid Reza Heiran ${ }^{\mathrm{c}}$ \\ Mohammad Javad Yavaric Siavash Motazedian ${ }^{\mathrm{b}}$ Maryam Dehghankhalili ${ }^{\mathrm{d}}$ \\ Departments of a Anesthesiology and ${ }^{b}$ Otolaryngology and ${ }^{\mathrm{C} S t u d e n t ~ R e s e a r c h ~ C o m m i t t e e, ~ F a s a ~ U n i v e r s i t y ~}$ \\ of Medical Sciences, Fasa, and ${ }^{\mathrm{d}}$ Student Research Committee, Hormozgan University of Medical Sciences, \\ Bandar-Abbas, Iran
}

\section{Key Words}

Postoperative pain $\cdot$ Ketamine $\cdot$ Adenotonsillectomy $\cdot$

Peritonsillar infiltration

\begin{abstract}
Objective: To evaluate the efficacy of preoperative intravenous or peritonsillar infiltration of ketamine for postoperative pain control in children following adenotonsillectomy. Patients and Methods: 78 children between 5 and 18 years of age who were scheduled for elective adenotonsillectomy were randomly assigned to four groups: group $1(n=19)$ received intravenous ketamine $(0.5 \mathrm{mg} / \mathrm{kg})$, group $2(\mathrm{n}=21)$ intravenous normal saline, group $3(n=19)$ ketamine $(0.5$ $\mathrm{mg} / \mathrm{kg}$ ) injected through the tonsillar capsule, and group 4 $(n=19)$ normal saline injected in the same location. The incidence of postoperative pain and vomiting as well as the severity of postoperative pain were compared between study groups during the 6-hour postoperative period using a visual analog scale (VAS) at rest, upon swallowing saliva, drinking liquids and eating ice cream. Results: There were no demographic differences between the four groups. The incidence of postoperative pain was significantly lower in groups 1 [7 (36.8\%) vs. 10 (47.6\%); $p=0.032]$ and 3 [5 (31.5\%) vs. $12(63.2 \%) ; p=0.001]$ compared with their controls. The
\end{abstract}

amount (in milligrams) of pethidine and metoclopramide used for pain and nausea control was significantly lower in groups $1(12.5 \pm 5.3$ vs. $19.6 \pm 9.6 \mathrm{mg}, \mathrm{p}=0.038$, and $2.9 \pm$ 1.1 vs. $4.6 \pm 2.6 \mathrm{mg}, \mathrm{p}=0.042$, respectively) and $3(8.6 \pm 3.1$ vs. $21.6 \pm 8.4 \mathrm{mg}, \mathrm{p}<0.001$, and $1.6 \pm 0.9$ vs. $5.3 \pm 3.2 \mathrm{mg}$, $p=0.002$, respectively) compared with their controls. These values were also higher in group 1 compared with group 3 . The VAS scores on swallowing saliva $(3.9 \pm 2.7$ vs. $2.7 \pm 1.2$; $p=0.018)$, on drinking liquids ( $3.7 \pm 2.6$ vs. $2.8 \pm 1.6 ; p=$ $0.013)$ and on eating ice-cream ( $4.3 \pm 2.4$ vs. $2.8 \pm 1.5 ; p=$ 0.001 ) were also significantly higher in group 1 compared with group 3. Conclusions: Our results show that peritonsillar infiltration of ketamine was more effective in reducing the postoperative pain severity, need for analgesics and need for antiemetics. Thus, peritonsillar infiltration of ketamine is suggested for postoperative pain control in those undergoing adenotonsillectomy.

Copyright $\odot 2011$ S. Karger AG, Basel

\section{Introduction}

Adenotonsillectomy is one of the most common procedures in pediatric otolaryngology. It also has significant postoperative complications, including bleeding,

\section{KARGER \\ Fax +41613061234 \\ E-Mail karger@karger.ch}

www.karger.com (c) 2011 S. Karger AG, Basel

1011-7571/11/0205-0433\$38.00/0

Accessible online at:

www.karger.com/mpp
Fariborz Ghaffarpasand

103 Biat Alley, Shuride Shirazi Street

PO Box 7173646199

Shiraz, Fars (Iran)

Tel. +98 9173095 214, E-Mail fariborz_ghaffarpasand@yahoo.com 
pain accompanied by odynophagia, laryngospasm, airway obstruction, sedation, nausea and vomiting. Odynophagia and pain can limit oral intake, and the resulting fibrinous plaques can cause infection, inflammation and postoperative bleeding [1]. Thus postoperative pain control is important. Many analgesics are still being recommended for postoperative pain control, including opioids, nonsteroidal anti-inflammatory drugs and local anesthetics, which are associated with sedation and respiratory depression, increased risk of reoperation for bleeding, and vasoconstriction of the operation site, respectively $[2,3]$.

Ketamine hydrochloride is a noncompetitive antagonist of the $N$-methyl-D-aspartate receptor and has analgesic properties in subanesthetic doses $[4,5]$. It produces dose-related unconsciousness and analgesia. Intraoperative intravenous ketamine at a dose of $0.2-0.8 \mathrm{mg} / \mathrm{kg}$ over 2-3 min has been shown to be effective in sedation and analgesia [4]. In the same way, intraoperative intravenous ketamine at a dose of $0.15 \mathrm{mg} / \mathrm{kg}$ has been shown to be effective in postoperative pain management [1]. Preoperative ketamine administration at $0.1 \mathrm{mg} / \mathrm{kg}$ intramuscularly has also been shown to decrease odynophagia following tonsillectomy [6]. Tverskoy et al. [7] showed that ketamine enhances the anesthetic and analgesic effects of local anesthetics used for infiltration in surgical patients via a peripheral mechanism. Both preoperative intravenous ketamine administration and peritonsillar infiltration at a dose of $0.5 \mathrm{mg} / \mathrm{kg}$ has been shown to be effective in postoperative pain control without significant side effects $[8,9]$. The aim of this study was to determine the efficacy of intravenous and peritonsillar infiltration of ketamine for postoperative pain relief in children undergoing adenotonsillectomy.

\section{Patients and Methods}

\section{Patients}

This study was a double-blinded, placebo-controlled, prospective clinical trial. Of 80 patients screened for the study, 78 American Society of Anesthesiologists physical status 1 and 2 patients of both sexes between the ages of 5 and 18 years who were scheduled for elective adenotonsillectomy were enrolled in the study. Patients with psychiatric illness, pulmonary and/or cardiac disease, peritonsillar abscess and analgesic usage within $24 \mathrm{~h}$ prior to surgery and/or a history of allergy to any of the study drugs, nausea and vomiting, motion sickness and gastrointestinal diseases were excluded from the study. All patients or their parents signed an informed consent form. The study was approved by the institutional ethics committee of the Fasa University of Medical Sciences.

\section{Study Protocol}

At the first visit, each patient was given a sealed envelope containing their admission number in the order of referral by a nurse (N. Mohammadi) who was blinded to the study. Patients were randomly assigned to four study groups using a computer-based randomization method: group $1(\mathrm{n}=19)$ received preoperative intravenous ketamine at a dose of $0.5 \mathrm{mg} / \mathrm{kg}$; group $2(\mathrm{n}=21)$ received $2 \mathrm{ml}$ intravenous saline preoperatively; group $3(\mathrm{n}=19)$ received peritonsillar infiltration of ketamine at a dose of $0.5 \mathrm{mg} /$ $\mathrm{kg}$, and group $4(\mathrm{n}=19)$ received peritonsillar infiltration of saline at $1 \mathrm{ml}$ per tonsil.

A preanesthetic assessment was conducted and the study protocol was explained to all patients the day before the surgery. All patients underwent the same anesthetic protocol: they received midazolam $(0.03 \mathrm{mg} / \mathrm{kg})$ as premedication, and anesthesia was induced with thiopental sodium $(3-5 \mathrm{mg} / \mathrm{kg})$ and atracurium $(0.4$ $\mathrm{mg} / \mathrm{kg}$ ). After 2-3 min of mask ventilation and reassurance of muscle relaxation, nasotracheal intubation was carried out. After intubation, group 1 received $0.5 \mathrm{mg} / \mathrm{kg}$ of ketamine intravenously, and group 2 received $2 \mathrm{ml}$ of normal saline intravenously. In group 3, ketamine $(0.5 \mathrm{mg} / \mathrm{kg})$ was injected through the tonsillar capsule and anterior plica, at $1 \mathrm{ml}$ per tonsil. A minimum duration of 3 min was allowed for the onset of action of the drug before adenotonsillectomy. This was repeated for group 4 with $1 \mathrm{ml}$ normal saline for each tonsil. All medications were $2 \mathrm{ml}$ in volume and were administered by one of the authors (S.K.), who was unaware of the content of the syringes.

Adenotonsillectomy with dissection and snare technique was performed on all patients by the same surgeon (S.M.), who was blinded to the allocation groups. Intraoperative bleeding was controlled using suturing. During maintenance of anesthesia, patients received a 50:50 combination of oxygen and nitrous oxide. After completion of surgery, neuromuscular blockade was reversed with neostigmine $(0.04 \mathrm{mg})$ and atropine $(0.02 \mathrm{mg} / \mathrm{kg})$. Patients were extubated when adequate spontaneous ventilation was established and transferred to the recovery unit. After approximately $1 \mathrm{~h}$, patients were transferred to their respective wards.

The presence of postoperative pain, nausea and vomiting, and the number of episodes and their severity were recorded by a physician (F.G.), who was blinded to the study. The severity of patients' pain and nausea was measured quantitatively using a 10$\mathrm{cm}$ linear visual analog scale (VAS) at 1,2, 4 and $6 \mathrm{~h}$ after the surgery at rest, on swallowing saliva, drinking liquids and eating ice cream. Pethidine $(0.5 \mathrm{mg} / \mathrm{kg})$ was given intravenously to patients who had a pain score of more than 4 . Patients who had a VAS score of more than 4 for nausea also received metoclopramide $(0.3 \mathrm{mg} / \mathrm{kg})$ intravenously. The patients' anxiety was assessed by a face-to-face interview using the Persian version of the Beck Anxiety Inventory [10]. Scores were interpreted as 'minimal' level of anxiety (0-7), 'mild' (8-15), 'moderate' (16-25) and 'severe' (26-63).

\section{Statistical Analysis}

Based on a power of 0.9 to detect a significant difference regarding postoperative pain on the VAS score ( $\mathrm{p}=0.05$, two-sided), 15 patients were required for each study group. To compensate for nonevaluable patients, we planned to enroll 20 patients per group. The Statistical Package for the Social Sciences - SPSS for Windows, version 15.0 (SPSS, Chicago, Ill., USA) - was used for data 
Table 1. Demographic characteristics of patients in four study groups

\begin{tabular}{|c|c|c|c|c|c|}
\hline & Group $1(n=19)$ & Group $2(n=21)$ & Group $3(n=19)$ & Group $4(n=19)$ & $\mathrm{p}$ \\
\hline Males & $5(6.4 \%)$ & $10(12.8 \%)$ & $5(6.4 \%)$ & $12(15.4 \%)$ & $0.054^{1}$ \\
\hline Females & $14(17.9 \%)$ & $11(14.1 \%)$ & $14(17.9 \%)$ & $7(8.9 \%)$ & $0.082^{1}$ \\
\hline Weight, kg & $24.3 \pm 6.4$ & $27.7 \pm 9.3$ & $26.3 \pm 10.1$ & $25.1 \pm 8.3$ & $0.595^{2}$ \\
\hline Height, $\mathrm{cm}$ & $136.5 \pm 16.4$ & $132.1 \pm 13.3$ & $135.2 \pm 15.8$ & $131.6 \pm 11.8$ & $0.710^{2}$ \\
\hline Duration of surgery, min & $17.5 \pm 5.2$ & $18.9 \pm 4.9$ & $18.3 \pm 5.2$ & $16.4 \pm 3.2$ & $0.373^{2}$ \\
\hline
\end{tabular}

Values denote means \pm SD unless specified otherwise.

${ }^{1}$ Using $\chi^{2}$ test. ${ }^{2}$ Using one-way ANOVA.

Table 2. Incidence of postoperative pain and analgesic need in four study groups

\begin{tabular}{|c|c|c|c|c|c|}
\hline & Group $1(n=19)$ & Group $2(n=21)$ & Group $3(n=19)$ & Group $4(n=19)$ & $\mathrm{p}$ \\
\hline Incidence of postoperative pain & $7(36.8 \%)^{1}$ & $10(47.6 \%)$ & $5(31.5 \%)^{2}$ & $12(63.2 \%)$ & 0.023 \\
\hline Incidence of postoperative vomiting & $3(15.7 \%)$ & $5(23.8 \%)$ & $2(10.5 \%)^{2}$ & $6(31.5 \%)$ & 0.046 \\
\hline Time to first analgesia, min & $166.56 \pm 93.3$ & $170.1 \pm 83.3$ & $165.1 \pm 59.2$ & $149 \pm 60.3$ & 0.961 \\
\hline Time to tolerate fluids, min & $172.1 \pm 47.4$ & $181.1 \pm 53.9$ & $170.8 \pm 62.2$ & $208.6 \pm 49.4^{2}$ & 0.212 \\
\hline Pethidine use, $\mathrm{mg}$ & $12.5 \pm 5.3^{1,3}$ & $19.6 \pm 9.6$ & $8.6 \pm 3.1^{2}$ & $21.6 \pm 8.4$ & $<0.001$ \\
\hline
\end{tabular}

Values denote means \pm SD unless specified otherwise.

${ }^{1} \mathrm{p}<0.05$, group 1 compared with group $2 .{ }^{2} \mathrm{p}<0.05$, group 3 compared with group $4 .{ }^{3} \mathrm{p}<0.05$, group 1 compared with group 3 .

analysis. The data on pain scores (VAS) were analyzed using a Kruskal-Wallis rank sum test. Differences among group means were compared using one-way ANOVA. For comparison between groups, Bonferroni was used as a post hoc test. Categorical variables were analyzed using the $\chi^{2}$ test. Data were reported as means \pm SD for $95 \%$ CI. A two-sided $\mathrm{p}<0.05$ was considered statistically significant.

\section{Results}

Of the 80 patients who were screened for the study, 2 refused to participate. None of the patients were excluded or lost to follow-up; thus the number of patients who finished the study was 78 . There were no demographic differences (gender distribution, age, weight, height, duration of surgery and duration of anesthesia) between the four study groups (table 1). There were no statistically significant differences between the groups in heart rate, change in mean arterial pressure and oxygen saturation during the surgery $(\mathrm{p}>0.05)$.
The incidence of postoperative pain and analgesic need for the four study groups is given in table 2 . The incidence of postoperative pain was significantly lower for groups 1 and 3 compared with their controls $(\mathrm{p}=0.032$ and $\mathrm{p}=0.001$, respectively). Patients in group 4 experienced a significantly higher rate of postoperative vomiting compared with group $3(\mathrm{p}=0.024)$. The number of patients who needed analgesics for pain control was lower in groups $1(\mathrm{n}=4 ; 21.1 \% ; \mathrm{p}=0.028)$ and $3(\mathrm{n}=3 ; 15.7 \%$; $\mathrm{p}=0.004)$ compared with their respective controls. The amounts (in milligrams) of pethidine and metoclopramide used for pain and nausea control were significantly lower in groups 1 ( $\mathrm{p}=0.038$ and $\mathrm{p}=0.042$, respectively) and 3 ( $\mathrm{p}<0.001$ and $\mathrm{p}=0.002$, respectively) compared with their controls. These values were also higher in group 1 compared with group 3 ( $\mathrm{p}=0.036$ for pethidine, and $\mathrm{p}=0.039$ for metoclopramide). There was no difference between groups regarding the time to first analgesic between groups $(\mathrm{p}=0.961)$. 
Table 3. Severity of postoperative anxiety and pain according to VAS in four study groups

\begin{tabular}{lllll}
\hline & Group 1 $(\mathrm{n}=19)$ & Group 2 $(\mathrm{n}=21)$ & Group 3 (n=19) & Group 4 (n=19) \\
\hline VAS score at rest & $2.8 \pm 1.9^{1}$ & $3.5 \pm 2.7$ & $2.4 \pm 1.3^{2}$ & $3.2 \pm 1.2$ \\
VAS score on swallowing saliva & $3.9 \pm 2.7^{3}$ & $3.7 \pm 1.9$ & $2.7 \pm 1.2^{2}$ & 0.043 \\
VAS score on drinking liquids & $3.7 \pm 2.6^{3}$ & $3.5 \pm 1.6$ & $2.8 \pm 1.6^{2}$ & $3.4 \pm 1.4$ \\
VAS score on eating ice-cream & $4.3 \pm 2.4^{3}$ & $4.4 \pm 1.8$ & $2.8 \pm 1.5^{2}$ & $3.4 \pm 1.6$ \\
Mild anxiety & $14(73.7 \%)^{3}$ & $14(66.6 \%)$ & $12(63.2 \%)^{2}$ & $3.6 \pm 1.7$ \\
Moderate anxiety & $4(21.1 \%)^{3}$ & $4(19.1 \%)$ & $6(31.6 \%)^{2}$ & 0.024 \\
Severe anxiety & $1(5.2 \%)^{1}$ & $3(14.3 \%)$ & $1(5.2 \%)^{2}$ & 0.023 \\
& & & $2(10.6 \%)$ & 0.621 \\
\end{tabular}

Values denote means \pm SD unless specified otherwise.

${ }^{1} \mathrm{p}<0.05$, group 1 compared with group $2 .{ }^{2} \mathrm{p}<0.05$, group 3 compared with group $4 .{ }^{3} \mathrm{p}<0.05$, group 1 compared with group 3 .

The severity of postoperative anxiety and pain in the four study groups is given in table 3 . The VAS score at rest was higher in groups $2(3.5 \pm 2.7 ; \mathrm{p}=0.031)$ and $4(3.2 \pm$ $1.2 ; \mathrm{p}=0.028)$ compared with their case groups. VAS scores on swallowing saliva $(\mathrm{p}=0.028)$, drinking liquids $(\mathrm{p}=0.029)$ and eating ice cream $(\mathrm{p}=0.022)$ were significantly higher in group 4 compared with group 3; however, there was no significant difference between groups 1 and 2 regarding these variables $(\mathrm{p}>0.05)$. VAS scores on swallowing saliva $(\mathrm{p}=0.018)$, drinking liquids $(\mathrm{p}=$ $0.013)$ and eating ice cream $(\mathrm{p}=0.001)$ were also significantly higher in group 1 compared with group 3 . The incidence of severe anxiety was significantly higher in groups $2(\mathrm{p}=0.023)$ and $4(\mathrm{p}=0.037)$ compared with their controls. The incidence of mild anxiety was significantly higher in group 1 compared with group $3(\mathrm{p}=0.025)$, while the incidence of moderate anxiety was lower in group 1 compared with group $3(\mathrm{p}=0.031)$.

\section{Discussion}

Our results show that both preoperative intravenous administration of ketamine and peritonsillar infiltration of ketamine reduced the incidence of postoperative pain and analgesic administration. The amounts of pethidine and metoclopramide used for pain and nausea control were significantly lower in those who received ketamine via both routes of administration. We also found that the amounts of analgesic and antiemetic used were significantly higher in those who received intravenous compared with peritonsillar infiltration of ketamine. In the same way, VAS scores at rest were significantly lower in the ketamine groups. However, VAS scores on swallowing, drinking liquids and eating ice cream were signifi- cantly lower in those who received peritonsillar infiltration of ketamine instead of intravenous administration. We found that patients who received preoperative intravenous infusion of ketamine had significantly less anxiety compared with those who received peritonsillar infusion of ketamine.

Dal et al. [8] compared the efficacy of preoperative intravenous administration with peritonsillar infiltration of ketamine in 30 children undergoing adenotonsillectomy. They found that low-dose ketamine given intravenously or by peritonsillar infiltration perioperatively provides efficient pain relief without side effects in children undergoing adenotonsillectomy. Nevertheless, they could not find any difference between the two case groups. They also did not include a control group with peritonsillar infiltration of saline. Their results are similar to ours regarding the fact that both intravenous and peritonsillar infusion of ketamine decreases postoperative pain, nausea and vomiting as well as VAS scores. However, we showed that peritonsillar infusion of ketamine is more effective than intravenous infusion. A similar study by Honarmand et al. [11] showed that a dose of either $0.5 \mathrm{mg} / \mathrm{kg}$ or $1 \mathrm{mg} / \mathrm{kg}$ of ketamine, using the peritonsillar infiltration method before adenotonsillectomy, reduced postoperative pain and need for analgesics compared with peritonsillar saline infusion. In our study, we used the $0.5 \mathrm{mg} / \mathrm{kg}$ dose for ketamine infusion both intravenously and peritonsillarly. We achieved the same results as Honarmand et al. [11] regarding the efficacy of peritonsillar administration of ketamine for posttonsillectomy pain control. However, our study presents new information about the better efficacy of peritonsillar infiltration of ketamine compared with intravenous administration. 
Our results are comparable with the results of the study by Aspinall and Mayor [12], in which intravenous administration of a dose of $0.5 \mathrm{mg} / \mathrm{kg}$ ketamine provided effective analgesia for the immediate postoperative period after adenotonsillectomy with no increased risk of side effects. However, Umuroğlu et al. [13] suggested that ketamine should not be used as an analgesic for adenotonsillectomy due to improper effects, i.e. heavy sedation and a low analgesic efficacy. Our results are consistent with those by Erhan et al. [9], who found that ketamine infiltration into the tonsillar region after tonsillectomy is an easy and effective method. The dose of ketamine used in this study caused no sedation or nausea and provided a high level of analgesia.

Our study is one of the first which overcame the limitation of some other studies in which there was no peritonsillar saline infiltration group. In this study, peritonsillar saline infiltration was used as a placebo for a group of children undergoing adenotonsillectomy to determine the effectiveness of peritonsillar infiltration of other medications.

\section{Conclusion}

Our study demonstrates that preoperative ketamine administration through the intravenous route and peritonsillar infiltration both reduce the incidence and severity of postoperative pain as well as the need for analgesics in children undergoing adenotonsillectomy. Peritonsillar infiltration of ketamine was more effective in reducing the postoperative pain severity, need for analgesics and need for antiemetics. Thus, peritonsillar infiltration of ketamine is suggested for postoperative pain control in those undergoing adenotonsillectomy.

\section{Acknowledgments}

We would like to thank all the patients and their families who participated in this study. We also wish to acknowledge Mrs. Nasrin Mohammadi for her technical assistance in randomization and registration. This study was financially supported by a grant (86-298) from Fasa University of Medical Sciences.

\section{References}

$>1$ O'Flaherty JE, Lin CX: Does ketamine or magnesium affect posttonsillectomy pain in children? Paediatr Anaesth 2003;13:413421.

-2 Marret E, Flahault A, Samama CM, Bonnet F: Effects of postoperative, nonsteroidal, antiinflammatory drugs on bleeding risk after tonsillectomy: meta-analysis of randomized, controlled trials. Anesthesiology 2003;98: 1497-1502.

$>3$ Møiniche S, Rømsing J, Dahl JB, Tramèr MR: Nonsteroidal anti-inflammatory drugs and the risk of operative site bleeding after tonsillectomy: a quantitative systematic review. Anesth Analg 2003;96:68-77.

4 Kochs E, Scharein E, Möllenberg O, Bromm B, Schulte am Esch J: Analgesic efficacy of low dose ketamine: somatosensory-evoked responses in relation to subjective pain ratings. Anesthesiology 1996;85:304-314.
-5 Dal D, Tetik O, Altunkaya H, Tetik O, Doral MN: The efficacy of intra-articular ketamine for postoperative analgesia in outpatient arthroscopic surgery. Arthroscopy 2004;20:300-305.

6 Elhakim M, Khalafallah Z, El-Fattah HA, Farouk S, Khattab A: Ketamine reduces swallowing-evoked pain after paediatric tonsillectomy. Acta Anaesthesiol Scand 2003;47:604-609.

7 Tverskoy M, Oren M, Vaskovich M, Dashkovsky I, Kissin I: Ketamine enhances local anesthetic and analgesic effects of bupivacaine by peripheral mechanism: a study in postoperative patients. Neurosci Lett 1996; 215:5-8.

$>8$ Dal D, Celebi N, Elvan EG, Celiker V, Aypar $\mathrm{U}$ : The efficacy of intravenous or peritonsillar infiltration of ketamine for postoperative pain relief in children following adenotonsillectomy. Paediatr Anaesth 2007;17:263269.

-9 Erhan OL, Göksu H, Alpay C, Beştaş A: Ketamine in post-tonsillectomy pain. Int J Pediatr Otorhinolaryngol 2007;71:735-739.
10 Beck AT, Epstein N, Brown G, Steer RA: An inventory for measuring clinical anxiety: psychometric properties. J Consult Clin Psychol 1988;56:893-897.

11 Honarmand A, Safavi MR, Jamshidi M: The preventative analgesic effect of preincisional peritonsillar infiltration of two low doses of ketamine for postoperative pain relief in children following adenotonsillectomy: a randomized, double-blind, placebo-controlled study. Paediatr Anaesth 2008;18: 508-514.

12 Aspinall RL, Mayor A: A prospective randomized controlled study of the efficacy of ketamine for postoperative pain relief in children after adenotonsillectomy. Paediatr Anaesth 2001;11:333-336.

13 Umuroğlu T, Eti Z, Ciftçi H, Yilmaz Göğüș F: Analgesia for adenotonsillectomy in children: a comparison of morphine, ketamine and tramadol. Paediatr Anaesth 2004;14: 568-573. 